\title{
Biobehavioral Indices of Emotion Regulation Relate to School Attitudes, Motivation, and Behavior Problems in a Low-Income Preschool Sample
}

\author{
ALISON L. MILLER, ${ }^{a}$ RONALD SEIFER, ${ }^{b}$ LAURA STROUD,${ }^{c}$ \\ STEPHEN J. SHEINKOPF ${ }^{b}$ AND SUSAN DICKSTEIN ${ }^{b}$ \\ ${ }^{a}$ University of Michigan School of Public Health, Ann Arbor, Michigan, USA \\ ${ }^{b}$ E.P. Bradley Hospital, Brown University Medical School, Providence, \\ Rhode Island, USA \\ ${ }^{c}$ Miriam Hospital, Brown University Medical School, Providence, \\ Rhode Island, USA
}

\begin{abstract}
Effective emotion regulation may promote resilience and preschool classroom adjustment by supporting adaptive peer interactions and engagement in learning activities. We investigated how hypothalamus-pituitary-adrenal axis (HPA) regulation, cardiac reactivity, and classroom emotion displays related to adjustment among low-income preschoolers attending Head Start. A total of 62 fouryear-olds completed a laboratory session including a baseline soothing video; emotion-eliciting slides/video clips, and recovery. Salivary cortisol, heart rate, and vagal tone were measured throughout. Independent coders used handheld computers to observe classroom emotion expression/regulation. Teachers rated child motivation, persistence/attention, learning attitudes, and internalizing/externalizing symptoms. Results reveal associations between biobehavioral markers of regulatory capacity and early school adjustment.
\end{abstract}

KEYWORDS: emotion regulation; reactivity; preschool; low-income; school readiness

\section{INTRODUCTION}

As early as preschool, low-income children show high rates of learning and behavior problems that can have a negative impact on classroom adjustment. ${ }^{1}$

Address for correspondence: Alison L. Miller, Ph.D., Department of Health Behavior and Health Education, University of Michigan School of Public Health, 1420 Washington Heights, SPHII, Room M5533, Ann Arbor, MI 48109-2029. Voice: 734-615-7459; fax: 734-615-2317.

e-mail: alimill@umich.edu

Ann. N.Y. Acad. Sci. 1094: 325-329 (2006). (C) 2006 New York Academy of Sciences. doi: 10.1196/annals.1376.043 
Modulating emotions and behaviors in the classroom setting is crucial for supporting the adaptive peer interactions and engagement in classroom learning activities that foster positive school attitudes and adjustment over time. ${ }^{2}$ In addition, psychophysiological reactivity and regulation in response to stress has been postulated to be an important aspect of a child's regulatory capacity. ${ }^{3,4}$ It is not clear, however, to what degree such different regulatory constructs are associated, and whether these aspects of regulatory ability relate differentially to child functioning in school. We address these questions in the current investigation.

In the current study, we examined relations among classroom emotion expression and regulation, psychophysiological stress reactivity and regulation, and early classroom adjustment. Specifically, we investigated how reactivity (heart rate, cortisol change) and regulation (RSA) in a laboratory task, and emotion expression and behavioral regulation as observed in the classroom setting were related. We also assessed how each of these indices of reactivity and regulation were associated with teacher ratings of school attitudes, motivation, and behavior problems. We studied these questions in a sample of low-income preschool children attending Head Start.

\section{METHOD}

\section{Participants}

Participants were 62 four-year-old children attending Head Start (45\% male). Participant information was reported for both race (67\% Caucasian, 13\% African American, 19\% biracial/other) and ethnicity (7\% Latino, 93\% nonLatino). Results reported here are based on a partial sample of an ongoing study of emotion processing in low-income children.

\section{Procedure}

Children were presented with emotion elicitation slides and brief video clips designed to elicit negative and positive valence and various arousal states. All stimuli were presented on a 15 -inch computer monitor and children were videotaped (data not presented here). Heart rate data were recorded continuously during the session. Children provided salivary cortisol samples at initial baseline, after a soothing video, after an arousing video, and recovery. Children's teachers completed questionnaires to assess school attitudes and behavior problems. Independent observers also observed children in their classrooms during "center-time" activities to assess behavior during relatively structured play periods. 


\section{Measures}

\section{Laboratory Session}

Reactivity variables were mean heart rate change from baseline to positive stimuli $[\mathrm{HR}(\mathrm{P})]$, mean heart rate change from baseline to negative $[\mathrm{HR}(\mathrm{N})]$, and mean cortisol change from baseline to negative [CORT(R)]. Regulation variables were baseline RSA [RSA(B)]; mean RSA change from baseline to positive $[\mathrm{RSA}(\mathrm{P})]$ and mean RSA change from baseline to negative $[\mathrm{RSA}(\mathrm{N})]$.

\section{Classroom Observations}

Handheld computers were used to conduct live observations (using "The Observer" software and the Psion Workabout, Noldus Technologies). Each child was observed 8 times for 10 min each. Seven mutually exclusive timebased emotion displays and dysregulation states were coded: Neutral, Positive, Mild Negative, Sadness, Anger, Emotionally Negative Dysregulation, and Neutral/Behavioral Dysregulation (e.g., highly active motor behavior). ${ }^{2}$ Coders recorded the onset and offset of each state, yielding a continuous stream of behavior states, which were reduced to yield a proportional duration score. Coders trained until they achieved intraclass correlations of 0.80 or greater for each code (overall reliability kappa $=0.73$ ).

\section{Teacher Reports}

Teachers completed the Preschool Learning Behavior Scale (PLBS), ${ }^{5}$ which included Motivation (e.g., shows interest in activities), Persistence (e.g., sticks to activity as long as can be expected for this age), and Attitude Toward Learning (e.g., willing to be helped) subscales as well as Total score $(0=$ does not apply; $2=$ most often applies). Teachers completed the Child Behavior Checklist-Teacher Report Form (CBCL-TRF) ${ }^{6}$ to assess externalizing and internalizing.

\section{RESULTS}

Positive emotion displays in class were marginally related to increased HR in response to positive stimuli $(r=0.23, P<0.10)$; sadness was marginally related to decreased HR in response to negative stimuli $(r=-0.23, P<0.10)$. Emotionally negative dysregulation was related to increased HR in response to negative stimuli $(r=0.26, P<0.05)$, and to less cortisol reactivity $(r=$ $-0.42, P<0.05)$. 
TABLE 1. Correlations: observed classroom emotions/behavior, school adjustment $[n=$ 61; TRF $n=20$ ]

\begin{tabular}{lrccccccc}
\hline $\begin{array}{l}\text { Teacher } \\
\text { Rating }\end{array}$ & Positive & Sad & Anger & $\begin{array}{c}\text { Mild } \\
\text { neg. }\end{array}$ & $\begin{array}{c}\text { Emot. } \\
\text { dysreg. }\end{array}$ & $\begin{array}{l}\text { Behav. } \\
\text { dysreg. }\end{array}$ & $\begin{array}{l}\text { Gleeful } \\
\text { taunting }\end{array}$ & Neutral \\
\hline Motivation & -0.05 & $-0.37^{*}$ & $-0.31^{*}$ & -0.03 & $-0.53^{*}$ & -0.09 & .05 & .16 \\
Persistence & 0.12 & -0.03 & $-0.19^{\dagger}$ & $-0.35^{*}$ & -0.04 & $-0.25^{\dagger}$ & -.16 & .02 \\
Learning Attitude & 0.00 & -0.05 & $-0.29^{*}$ & $-0.27^{*}$ & -0.15 & -0.08 & -.05 & .08 \\
Overall Learning & 0.06 & $-0.23^{\dagger}$ & $-0.31^{*}$ & -0.19 & $-0.31^{*}$ & -0.15 & .03 & .07 \\
CBCL-TRF-Ext & -0.16 & 0.20 & $0.49^{*}$ & $0.55^{*}$ & -0.02 & 0.19 & .26 & .01 \\
CBCL-TRF-Int & -0.11 & 0.04 & $0.40^{*}$ & 0.18 & $0.44^{*}$ & 0.11 & .30 & .03 \\
\hline
\end{tabular}

${ }^{*} P<0.05 ;{ }^{\dagger} P<0.10$.

We next examined relations between reactivity and regulation and teacherrated school adjustment. Motivation was marginally related to increased HR in response to positive stimuli $(r=0.23, P<0.10)$ and persistence marginally related to decreased HR in response to negative stimuli $(r=-0.23, P<$ $0.10)$. Teacher ratings of motivation and overall learning behaviors were related to greater cortisol reactivity $(r=0.65$ and 0.52 , respectively, $P<0.05)$. We also found that negative emotion expression (particularly anger) related to motivation, persistence, learning attitudes, and behavior problems (see TABLE 1).

\section{DISCUSSION}

We observed some relations among stress reactivity (primarily heart rate) and emotion displays in the classroom setting, although on balance associations were modest. We did not find relations between regulation (RSA) and classroom displays. It may be that with regard to classroom functioning, a child's reactivity may have a greater impact than his or her baseline regulatory ability (as indexed by RSA).

More associations were found for observed classroom emotion displays and teacher-rated school adjustment than for the laboratory-based measures; among the laboratory-based measures, reactivity (vs. regulation) variables were somewhat more strongly related to teacher ratings. Specifically, cortisol reactivity was strongly related to teacher-rated motivation and overall positive learning/school attitudes, possibly suggesting that higher levels of reactivity may actually be beneficial for effective engagement in the school setting and with classroom activities. Although interesting, interpretation must be tempered by the fact that only a small subset of children $(n=20)$ had cortisol data; analyses are ongoing and this question will be investigated in more detail using the full sample. 
Considering context (i.e., naturalistic vs. lab based) and level of assessment (i.e., observed behavioral vs. psychophysiological) is crucial when studying regulatory processes. We found that public aspects of regulation and reactivity (e.g., observed emotions in the classroom) had more to do with teachers' views of child functioning at school than did more private/internal aspects of a child's regulatory abilities as assessed in the laboratory setting. It is likely that effective emotion regulation skills at multiple levels are an important part of school readiness and may augment the effects of programs such as Head Start, which is designed to promote resilience for children living in poverty circumstances.

\section{REFERENCES}

1. Harden, B.J., M.B. Winslow, K.T. Kendziora, et al. 2000. Externalizing problems in Head Start children: an ecological exploration. Early Educ. Dev. 11: 357-385.

2. Miller, A.L., K.K. Gouley, R. Seifer, S. Dickstein \& A. Shields. 2004. Emotions and behaviors in the Head Start classroom: associations among observed dysregulation, social competence, and preschool adjustment. Early Educ. Dev. 15: $147-165$.

3. Blair, C., D. Granger \& R.P. Razza. 2005. Cortisol reactivity is positively related to executive function in preschool children attending Head Start. Child Dev. 76: 554-567.

4. Porges, S.W. 2001. The polyvagal theory: phylogenetic substrates of a social nervous system. Int. J. Psychophysiol. 42: 123-146.

5. McDermott, P.A., L.F. Green, J.M. Francis \& D.H. Stott. 2000. The Preschool Learning Behaviors Scale. Edumetric \& Clinical Science. Philadelphia, PA.

6. AchenbaCH, T.M. \& L.A. Rescorla. 2000. Manual for ASEBA Preschool Forms \& Profiles. University of Vermont, Research Center for Children, Youth, \& Families. Burlington, VT. 